\title{
MATHEMATICS IN CONTEXT: CALL OF TIME
}

\author{
Abdul Quaiyum \\ Department of Mathematics Education
}

\begin{abstract}
Mathematics in context (MiC) is an integrated program that uses Realistic Mathematics Education(RME) approach to teaching and learning of mathematics. It emphasizes learning mathematics from realistic situations, students' invention or construction of solution procedure and interaction with other students or the teacher. Students should be encouraged to make sense out of real problems and the mathematics instruction should be designed accordingly. This article deals with the underlying principles of RME and highlights the features of MiC in Nepalese Mathematics Education.
\end{abstract}

\section{Keywords}

Realistic Mathematics Education (RME), Mathematics in Context (MiC), didactical phenomenology, guided reinvention, emergent model

\section{Introduction}

Over the last four decades, mathematics education around the globe has changed considerably. The paradigm shifted from a mechanistic to a structuralistic approach which again has moved to a realistic approach in school education recently. According to the mechanistic point of view, mathematics is a system of rules and algorithm. The emphasis is on step-wise approach, memorizing, verifying and applying these rules to problems that are similar to previous ones. In the structuralistic view, mathematics is an organized deductive system. The process of learning first starts from mathematical structure and then is applied to the solutions of problems. On the contrary, mathematics, in the realistic view, is a human activity and therefore must be connected to reality. The emphasis is on construction of mathematical knowledge by giving meaning to problems from real-world contexts (Wubbles et al. 1997).

In realistic approach, a real- world situation or context problem is taken as starting point of learning mathematics. Students are challenged to develop their own strategies for 


\section{A. Quaiyum}

solving real- world problems and to discuss these with other students. Finding solutions to real- world problems is not the end of mathematicslessonsinthisapproach. Teachers help the children to develop their informal strategies into more formal approaches which they can use in other situations (Treffers, 1987). This, however, contradicts largely with teaching of mathematics in Nepalese contexts where structuralistic approach has been in practice. In this approach the context may at times be used to introduce a topic and later to application, but most of teaching and learning mathematics takes place out of context. The skills are practiced and only then applied to solution of problems. This practice does not equip students with the desired conceptual understanding and problem-solving skills. Consequently, there is widespread concern about students' achievement and in particular their ability to apply mathematics both in higher education and in employments (Sharma, 2011).

With this perspective, a high level interaction program on 'Mathematics in Context (MiC)' was organized in Kathmandu with the collaboration of South Korean educationists who have developed and have been practicing $\mathrm{MiC}$ in their local contexts. Discussion papers were presented and interactions were held on the issues of adopting $\mathrm{MiC}$ as a reform in mathematics education for making the teaching and learning of mathematics realistic and meaningful.

\section{Principles and implications of RME}

Realistic Mathematics Education (RME) is rooted in 'mathematics as a human activity. The term 'realistic' refers to not just the connection with the real-world, but also an emphasis that RME puts on offering students problem situations which they can imagine. The underlying principles of RME are guided reinvention, didactical phenomenology and emergent models. These principles are based on Freudenthal's philosophy which emphasizes reinvention through progressive mathematization (Freudenthal, 1991). In RME, context problems are the basis for progressive mathematization and through mathematizing, the students develop informal context-specific solution strategies from experientially realistic situations (Gravemeijer \& Doorman, 1999). The instructional design perspective of RME is to utilize contextual problems that allow for a wide variety of solution procedures and students are constantly encouraged to reflect on these and refine them through a process of progressive mathematization (Kwon, 2003).

In RME instructional design, the first heuristic is reinvention through progressive mathematization.Accordingtothereinvention principle, students are given the opportunity to experience a process similar to the process by which the mathematics was invented. This principle suggests that instructional activities should provide students with experientially realistic situations and by facilitating informal solution strategies, students should have an opportunity to invent more formal mathematical practices. The history of mathematics can be a source of inspiration for solving experientially real problems for which they do not know the standard solution procedures yet (Streefland, 1991; Gravemeijer, 1994) as starting points. Then the teacher formulates a tentative learning sequence by a progressive mathematization.

The second RME heuristic is didactical phenomenology. Freudenthal (1973) defines didactical phenomenology as the study of the relation between the phenomena that the mathematical concept represents and the concept itself. In this phenomenology, the focus is on how mathematical interpretations make phenomena accessible for reasoning and calculation. The didactical phenomenology can be viewed as a design heuristic because it suggests the ways of identifying possible instructional activities that might support individual activity and whole-class discussions where the students engage in progressive mathematization (Gravemeijer, 
1994). Thus the goal of the phenomenological investigation is to create settings in which students can renegotiate increasingly sophisticated solutions to experientially real problems by individual activity and wholeclass discussions (Gravemeijer, Cobb, Bowers \& Whitewack, 200o).

The third RME heuristic for instructional design focuses on the role which emergent models play in bridging the gap between informal knowledge and formal mathematics. The term model is understood in a dynamic and holistic sense. As a consequence, the symbolizations that are embedded in the process of modeling and that constitute the model can change over time. Thus, students first develop a 'model- of' a situated activity and this model later becomes a 'model -for' more sophisticated mathematical reasoning (Gravemeijer \& Doorman, 1999). Models also allow students to work at differing levels of abstraction so that those, who have difficulty with more formal notions, can still make progress.

A fundamental issue that differentiates RME from an exploratory approach is the manner in which it takes account both of the collective mathematical development of the classroom community and of the mathematical learning of the individual students who participate in it. Thus, RME is aligned with recent theoretical developments in mathematics education that emphasizes socially culturally situated nature of mathematical activity (Kwon, 2003).

\section{Mathematics in Context (MiC) program}

MiC program is based on the philosophy of Realistic Mathematics Education (RME) that was originally developed by $\mathrm{H}$. Fueudenthal in The Netherlands in the early seventies. RME theory has been used successfully over many years in many countries. Mic emphasizes the dynamic, active nature of mathematics and the way mathematics enables students to make sense of their world (Meyer, 2001).

Curricular change: $\mathrm{MiC}$ advocates a comprehensive curriculum whose key feature is connections- connections among topics, to other disciplines and between mathematics and meaningful problems in the real world.

Many reform movements are rather aimed at getting rid of textbooks. However, in MiC, the improvement of mathematics education is carried for a considerable part by the textbooks. Textbooks have a determining role and are used as most important tools that guide the teaching and learing activites.

Change in instructional approach: In traditional approach, the sequence of teaching often proceeds from a generalization, to specific examples and finally to application in context. The MiC approach reverses this sequence: and introduces concepts within realistic contexts that support mathematical abstraction. Mathematical tasks and questions are designed to stimulate mathematical thinking and to promote discussions among students. Students are expected to explore mathematical relationships, develop and explain their own reasoning and strategies for solving problems and use problem-solving tools appropriately (Romberg, 2001).

Change in students' practice: In MiC, students are encouraged to make sense of the contexts using their experiences, intuitions and common sense. They then stay in contexts and remain at a sense making level while they develop mathematical skills/concepts. MiC promotes the development of more formal methods from students' informal methods. It allows students to continue to be able to use informal methods rather than relying on the methods used by teachers.

Change in teacher's practice: In MiC approach, the teacher's role changes significantly owing to its greater emphasis on problem situations. Students are given a problem to read and start working on, and they are likely to come up with strategies and techniques that are different from the teacher's. Traditionally, the approach to problem has been "Here's a problem. Let 


\section{A. Quaiyum}

me show how to do it. Now we are going to do more problems than one". The approach of $\mathrm{MiC}$ is, "Here's a problem. Our (students and teacher) job collectively is to figure out how we are going to make sense out of it". The role of the teacher is, thus, much more as the director of the discussions that will lead to a rediscovery of significant mathematics. The teacher helps students compare alternative ways to looking at problems and to figure out what's correct because there is not always clear answer (Meyer, 2001).

Many teachers initially may have some difficulty with this change in instructional approach. The children are working on a problem and the job of a teacher is not to tell them what to do; but rather to support in what they are doing, to challenge their ideas, to get them to share their thinking, to get them to argue about mathematics. Building arguments is a central part of what learning to do mathematics is all about (Romberg, 2001). There are a lot of management issues that are related to curriculum, organization of materials, grouping of children and management of discussions.

\section{Conclusion}

Mic uses real contexts as both a route into mathematics and also as a means of developing students' understanding. It provides students with a sequence of realistic problems, often based on the historical development of mathematical concepts. Students are led to reinvent mathematics for themselves and gradually use increasingly sophisticated methods for solving problems. Having understood that Mic approach has a large number of advantages over tradional approaches, I propose that $\mathrm{MiC}$ approach is adopted in Nepal to make mathematics instruction more meaningful and realistic. Additionally, since $\mathrm{MiC}$ approach has fetched more success in many countries of the world, Nepalese mathematics should not delay in owning it. Nepal is characterized by social, cultural and ethnic diversities and
$\mathrm{MiC}$ approach is hoped to address the issue of diversities contextually. This approach will provide students an opportunity to use mathematics, increase understanding of mathematical concepts and improve problem solving skills.

\section{References}

Freudenthal, H. (1973). Mathematics as an educational task. Dordrecht: Kluwer Academic Publishers.

(1991). Revisiting mathematics education. Dordrecht: Kluwer Academic Publishers.

Gravemeijer, K. (1994). Educational development and developmental research in mathematics education. Journal for Research in Mathematics Education, 25(5), 443-471.

Gravemeijer, K., \& Doorman, M. (1999). Context problems in realistic mathematics education: a calculus course as an example. Educational Studies in mathematics, 39, 111-129.

Gravemeijer, K., Cobb, P., Bowers, J., \& Whitenack, J. (2000). Symbolizing, modeling and instructional design. In P. Cobb, E. Yackel \& K. McClain (Eds.), Symbolizing and communicating in mathematics classrooms (pp 225-273) Mahwah, NJ: Erlbaum.

Kwon, O. N. (2002). The effects of calculator - based ranger activities on students graphing ability. School Science $\mathcal{E}$ Mathematics, 102(2), 5-15. ..(2003)

Conceptualizing the realistic mathematics education approach in the teaching and learning of ordinary differential. School Science $\mathcal{E}$ Mathematics, 105(3), 1-9.

Meyer, M. (2001). Mathematics in Context. Madison: Education Development Center, Inc. 
Romberg, T. A. (2001). Mathematics in Context. Madison: Education Development Center, Inc.

Streefland, L. (1991). Realistic Mathematics Education in Primary School. Dordrecht: Kluwer Academic Publishers.

Sharma, L. (2011). Need of reconceptualising curriculum, textbook and workbook in the perspective of Mathematics in Context. A discussion paper presented in Kathmandu on January 26, 2011.
Treffers, A. (1991). Realistic mathematics education in the Netherlands. In L. Streefland (ed.), Realistic mathematics education in primary school. Dordrecht: Kluwer Academic Publishers.

Wubbles, T., Korthagen, F., \& Broekman, H. (1997). Preparing teachers for Realistic Mathematics Education. Educational Studies in Mathematics, 32, 1-28.

\section{The Author}

Abdul Qaiyum is a Professor of Mathematics Education in Thakur Ram Multiple Campus, Birgunj, where he teaches courses such as Mathematical Statistics, Projective Geometry and Research Methodology. He has been associated with teaching and research for the last thirty five years. $\mathrm{He}$ is a Ph. D. from Univeristy of Lucknow(India). His area of intrest include Problem-solving in Mathematics. He particpated in a training on mathematics teaching in the Phillipines(1985). To his credit, he has extensively published papers on Mathematics Education in acclaimed journals. Currently, he is the President of Research Society of Integrated Society(RESIS), Birgunj and an exectuvie editor of its journal. He is a life member of Council for Mathematics Education.

Email:drabdulquaiyum@yahoo.com 